\title{
DIHYDROGENATED ALKALOIDS OF ERGOT IN THE INVESTIGATION AND TREATMENT OF DIASTOLIC HYPERTENSION
}

\author{
BY \\ DONALD F. GIBBS* \\ From Royal Infirmary, Edinburgh
}

Received May 6, 1951

The treatment of essential diastolic hypertension by surgical sympathectomy has given benefit to properly selected patients (Keith et al., 1949). It is reasonable to suppose that adrenergic blockading agents may also be beneficial in the treatment of hypertension, producing a " chemical " sympathectomy.

The fact that crude extracts of ergot produce sympatholytic activity as well as being direct stimulators of smooth muscle was recognized by Dale (1906). He pointed out that administration of such extracts brought about a subsequent paralysis of motor elements having sympathetic innervation and normally stimulated by adrenaline, while inhibitive elements in the same structures were unaffected. Subsequent chemical purification of the crude drug resulted in the isolation of several alkaloids including ergotamine (Stoll, 1920), ergokryptine, ergocornine, and ergocristine (Stoll and Hofmann, 1943). By hydrogenating the reducible double bond of the lysergic acid component of these parent alkaloids, a new series of compounds was produced, namely dihydroergotamine, dihydroergokryptine, dihydroergocornine (Stoll and Hofmann, 1943), and dihydroergocristine.

The actions of these reduced alkaloids differ somewhat from those of the parent alkaloids. Firstly, the adrenergic blocking potency of the reduced alkaloid is always greater than that of the parent compound (Nickerson, 1949). In vitro tests on guinea-pig seminal vesicle and rabbit uterus suggest that dihydroergotamine is the least potent and dihydroergokryptine the most potent in this respect. This adrenergic blocking action is probably next in potency to that produced by the . B-halo-alkylamines (Nickerson, 1949).

Secondly, the dihydro compounds are less active in the direct stimulation of smooth muscle. They not only fail to stimulate rabbit or guinea-pig uterus in vitro (Rothlin, 1947; Rothlin and Cerletti, 1949), but also tend to diminish uterine contraction and to inhibit the stimulant effects of ergotamine and ergometrine on the uterus. Similarly, hydrogenation reduces but does not eliminate the vaso-constrictor actions of the ergot alkaloids (Cerletti and Kallenberger, 1948).

Thirdly, toxicity is reduced by hydrogenation.

The action of these substances on the central nervous system is a mixture of stimulation and depression, but data are limited concerning the dihydro alkaloids.

The extent of adrenergic blockade produced by the dihydro alkaloids in man remains to be thoroughly investigated, and it is important that changes should not be ascribed to these actions which are really due to central vasomotor depression.

Subjects differ in their clinical response to the various dihydro alkaloids mentioned (von Kappert et al., 1949), and in an attempt to minimize these individual variations a mixture of equal parts of

* Work done during tenure of a Crichton Research Scholarship, University of Edinburgh. 
dihydroergocornine, dihydroergocristine, and dihydroergokryptine was introduced under the name of hydergine (Sandoz).

It was decided by way of preliminary observation to investigate the effect of intravenous injection of a suitable test dose of hydergine in subjects with diastolic hypertension and also to observe the effect of combined oral and intramuscular therapy. Oral therapy alone with dihydroergocornine produced no significant change in blood pressure in the ten cases reported by Bello et al. (1950), but these authors observed some fall in pressure following intravenous administration of this alkaloid, as did Bluntschli and Goetz (1947).

\section{The INTRAVENOUS TeST}

Materials and Methods. Fifty consecutive patients, each of whom had diastolic hypertension and were under observation, received the intravenous test. Of these patients 3 had malignant hypertension and 47 had benign hypertension. Of the former, 2 were women and $1 \mathrm{a}$ man, and of the latter, 31 were women and 16 men. Thirty-three of the benign cases had essential hypertension; 7 had had toxæmia of pregnancy, and 7 had a history suggestive of renal disease. Two of the malignant cases fell into the essential category and the other had suffered from acute pyelonephritis on at least two occasions. The ages ranged from 18 years to 65 years. Forty-one of the patients were in bed in hospital at the time of the test and the remaining 9, who had previously been investigated in hospital, returned as out-patients for the test. No form of treatment was carried out at the time of the test, save that phenobarbitone, $\frac{1}{2}$ grain t.i.d., had been given in all cases for more than four days before the test; there is no reason to suppose that this should in any way vitiate the results obtained.

Technique. The test was carried out as follows: the subject was put at rest in bed behind screens in the ward at a quiet time, or, in the case of out-patients, in a quiet room. The blood pressure was estimated at two-minute intervals over a period of 20-40 minutes for in-patients, and one hour for out-patients, so that a base line level was reached under conditions as near to basal as were reasonably possible. An injection of $0.3 \mathrm{mg}$. of hydergine (containing $0.1 \mathrm{mg}$. of each of the three alkaloids) was then given intravenously diluted in $5 \mathrm{ml}$. of normal saline. In 10 patients, it was given over a period of two minutes, as generally recommended. In 10 patients, it was given over a period of one minute, and in 30 patients it was given over a period of 30 seconds. The blood pressure was then taken every two minutes for the first ten minutes, and then every five minutes for the next fifty minutes, following which it was estimated at half-hourly periods.

Results. In all patients the blood pressure was lowered following injection. In every case, the fall in blood pressure commenced within ten minutes of completion of the injection. The figures quoted for the average fall in each group were estimated from the maximum fall which occurred in the subjects mentioned: in each case this fall occurred within one hour, generally within 10-30 minutes.

Patients with benign hypertension fell into two groups in relation to the amount of fall in pressure: (a) those with good renal function and minimal arteriosclerosis (41 cases) in whom the average resting pressure was $189 / 113 \mathrm{~mm}$., and the average fall was $36 \mathrm{~mm}$. systolic and $20 \mathrm{~mm}$. diastolic (Fig. 1A); (b) those with poor renal function and/or marked arteriosclerosis (6 cases) in whom the average resting pressure was $232 / 126 \mathrm{~mm}$. and the average fall $20 \mathrm{~mm}$. systolic and $11 \mathrm{~mm}$. diastolic (Fig. 1B).

The three cases with malignant hypertension all had good renal function and no arteriosclerotic change of significance; the pressure falls were from $246 / 144$ to $196 / 112 \mathrm{~mm}$. in one; from $258 / 142$ to $202 / 108 \mathrm{~mm}$. in another, and from $232 / 152$ to $182 / 124 \mathrm{~mm}$. in the third (Fig. 2).

The depression of blood pressure lasted over a variable period of up to $1 \frac{1}{2}$ hours. The systolic pressure fell in direct proportion to the diastolic pressure, but there was no significant statistical 
relation between the initial resting diastolic pressure and the amount of fall of diastolic pressure. The comparison with the response of the blood pressure to the sodium amytal test showed that on the whole lability of the pressure as indicated by this latter test was also indicated by hydergine, although it was impossible to foresee which would cause a greater fall in pressure in any given subject. The injection time was not related to the rapidity of fall in pressure.

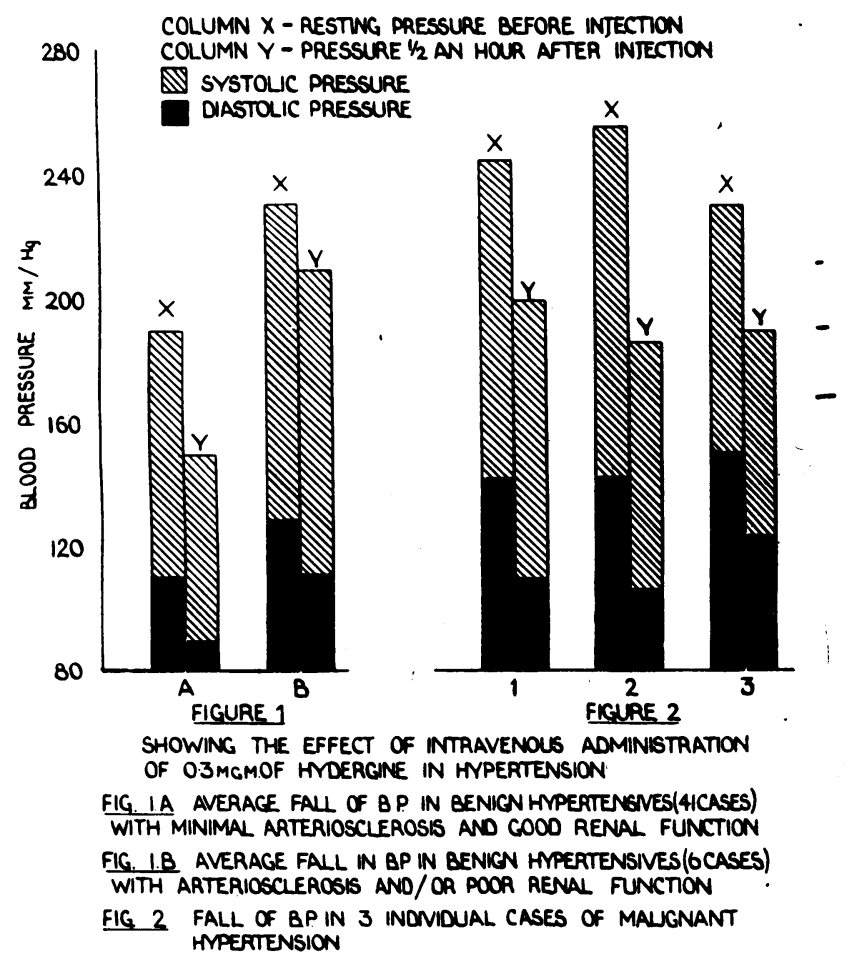

Before each test, a drop of homatropine was put in one eye of the subject, and observation made of the state of the retinal arterioles, particularly of the amount of spasm present. In 11 subjects, including the three malignant cases, there was marked spasm before injection, and in every one of these the arterioles were observed to " open out" within ten minutes of completion of injection. This effect lasted up to 12 hours in nine cases, and was still present after 24 hours in two.

In all subjects, including the three malignant cases, the cold pressor test was carried out before and half an hour after injection of hydergine. The response to cold in the form of a rise in pressure, both systolic and diastolic, was diminished following the injection of hydergine.

The average rise in pressure in the group of benign cases, with good renal function and minimal arteriosclerosis, following application of the cold stimulus was $42 \mathrm{~mm}$. systolic and $28 \mathrm{~mm}$. diastolic, and half an hour after hydergine was injected the average rise was $14 \mathrm{~mm}$. systolic and $10 \mathrm{~mm}$. diastolic (Fig. 3). In the second group, those with poor renal function and/or arteriosclerosis, the average rise before injection was $22 \mathrm{~mm}$. systolic and $16 \mathrm{~mm}$. diastolic, and after injection was $15 \mathrm{~mm}$. systolic and $9 \mathrm{~mm}$. diastolic (Fig. 4). In the three malignant cases, the rise in pressure averaged $48 / 32 \mathrm{~mm}$. before, and 17/10 mm., after injection (Fig. 5.)

The only side-effect noted was nasal congestion in 11 cases, lasting for hal fto one hour. 


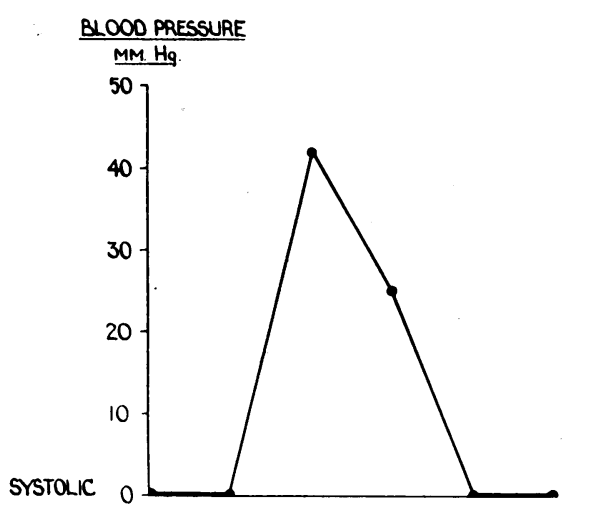

(2)

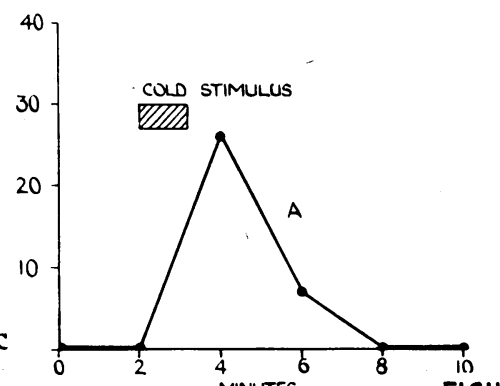

DIASTOLIC

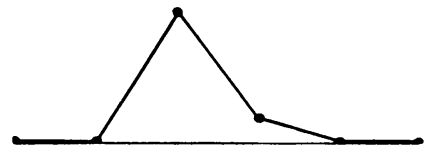

COLO STIMULUS WII THE EFFECT OF HYDERGINE ON THE COLD PRESSOR TEST IN BENIGN CASES OF HYPERTENSION WITH MINIMAL ARTERIOSCLEROSIS AND GOOD RENAL FUNCTION (AVERAGE RESPONSE 4I CASES)

A COLD PRESSOR RESPONSE BEFORE HYDERGINE

B COLD PRESSOR RESPONSE $1 / 2$ AN HOUR AFTER ADMINISTRATION OF O3 MOM HYDERGINE BY INTRAVENOUS INJECTION

\section{TREATMENT}

Seventeen patients were selected for treatment, and the effects thereof were observed over a period of at least six months in 12 cases, four months in 4 cases and three months in the other. Sixteen of these subjects had benign hypertension and of these 8 had essential hypertension, 4 had had toxæmia of pregnancy and 4 had a history suggestive of renal disease; the other case had malignant essential hypertension. The only factor excluding a patient from a therapeutic trial was the occurrence of either left ventricular heart failure or congestive heart failure before or at admission. Each patient on admission to hospital had a careful history taken, with particular reference to obstetric and renal factors. For the first week in hospital, a series of investigations was carried out, including the intravenous hydergine test, the urea range test, retinal examination estimation of heart size, a full set of unipolar electrocardiographic leads, and in each case $F 933$ (piperidyl-methyl-benzodioxane) was administered by intravenous injection to exclude possible pheochromocytoma. Blood pressure was estimated daily with the same sphygmomanometer at the same hour every morning by the same investigator. Readings were taken on each occasion over a period of 15-30 minutes until a constant base line was obtained.

For the first 10 to 14 days, the patients were treated by rest in bed and phenobarbitone $\frac{1}{2}$ grain t.i.d. was the only drug administered. They were allowed up for toilet purposes and for one to three hours in the evenings.

During the third week, an inert preparation of the same taste, smell, appearance, and dispensed from the same bottles as the active preparation, was administered by mouth in the same dosage used for the active preparation. This inert preparation for oral dosage consisted of nux vomica 


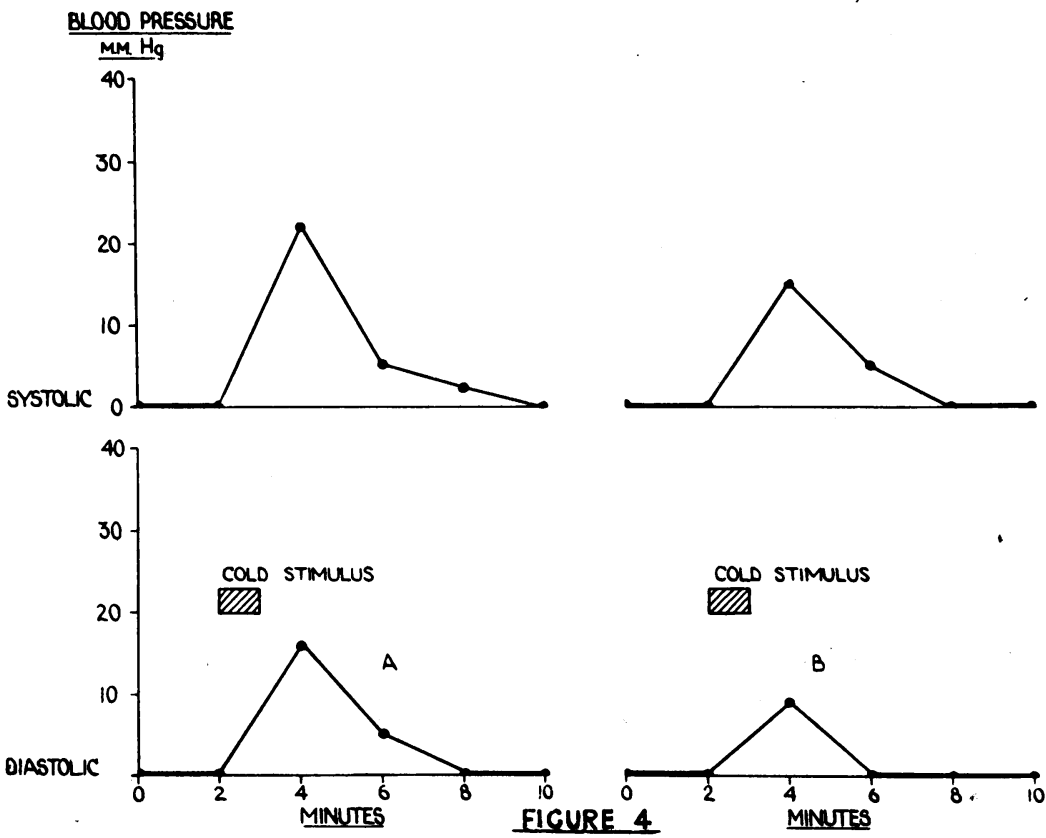

THEEFFECT OF HYDERGINE ON COLD PRESSOR TEST IN BENICN CASES OF HYPERTENSION WTH ARTERIOSCLEROSIS AND/OR POOR RENAL FUNCTION. (AVERACE RESPONSE FOR OCASES)

A. COLD PRESSOR RESPONSE BEFORE HMDERGINE

B. COD PRESSOR RESPONSE $1 / 2$ HOUR AFTER AOMINSTRATION OF 0.3MEA HMDERGINE BY INTRAVENOUS INTECTION

10 minims, glycerine 1 drachm, water to $2 \mathrm{oz}$; $1 \mathrm{ml}$. of normal saline was given by intramuscular injection daily. In no case did patients know that an inert substance was being given, and all realized that the treatment was being undertaken to investigate its value on their illness.

At the end of this week, three days were allowed to elapse and then hydergine was started by mouth and intramuscular injections for a period of fourteen days in the following dosage:

$\begin{array}{rcc}\text { Day } & \begin{array}{c}\text { Oral dose } \\ \text { minims t.i.d. }\end{array} & \begin{array}{c}\text { Intramuscular dose } \\ \text { ml. }\end{array} \\ 1 & 5 & 0.5 \\ 2 & 8 & 0 \cdot 5 \\ 3 & 11 & 1.0 \\ 4 & 14 & 1.0 \\ 5 & 17 & 1.0 \\ 6 & 20 & 1.0 \\ 7 & 23 & 1.0 \\ 8 & 25 & 1.0 \\ 9 & 25 & 1.0 \\ 10 & 25 & 1.0\end{array}$

Thereafter 35 minims orally t.i.d.

$1 \mathrm{minim}$ of oral solution contains $0.0195 \mathrm{mg}$. of each alkaloid. $1 \mathrm{ml}$. of parenteral solution contains $0.1 \mathrm{mg}$. of each alkaloid. 


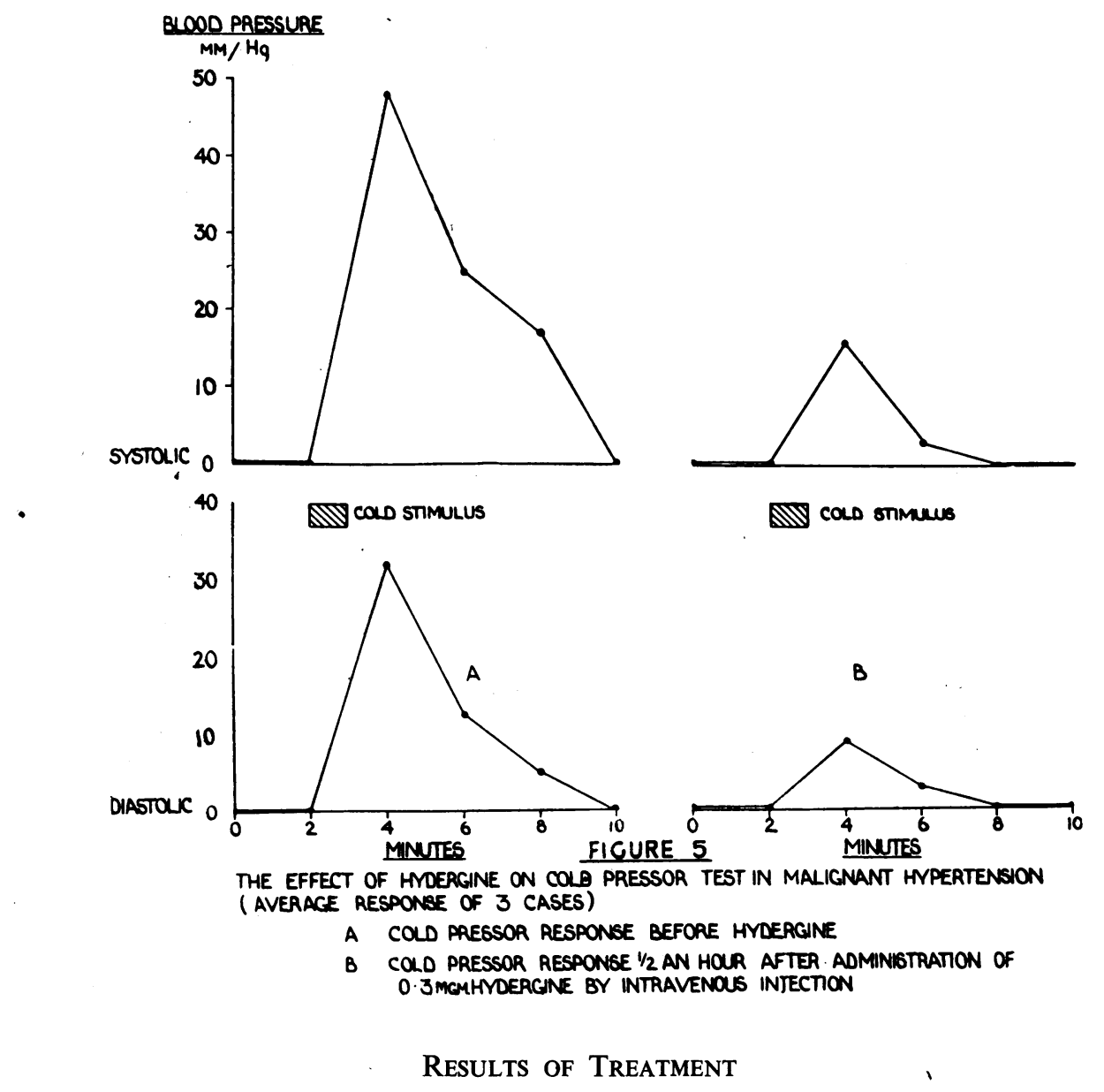

(a) While in hospital

(1) Effects on blood pressure. This will be seen from consideration of Table I. In all cases there was some drop in blood pressure as compared with the reading prior to treatment and that during administration of the inert substance. The drop in pressure was considered to be significant in 12 cases, in whom the fall in diastolic pressure was greater than $14 \mathrm{~mm}$. $\mathrm{Hg}$ as compared with the inert control period. The drop in pressure while on the inert substance was never more than $10 \mathrm{~mm}$. diastolic, as compared with the previous period.

The 5 cases that did not respond in a significant fashion had poor renal function in four instances, and of these, 3 showed marked retinal and peripheral arteriosclerosis and the other (Case 1) was aged 25 years and had chronic nephritis. The case with normal renal function was markedly arteriosclerotic. None of these had shown a fall of over $18 \mathrm{~mm}$. systolic and $10 \mathrm{~mm}$. diastolic during the intravenous test dose.

(2) Effect on symptoms. Symptomatic improvement was noted in 13 cases, and in 10 of these complete relief of symptoms was observed. In no case were the symptoms aggravated, although three showed no change in the symptoms, and one had no symptoms.

Of the three cases who obtained no relief of symptoms, two were mentally unstable, and the other had severe side-effects.

The symptoms that were relieved consisted of tiredness and headache in all instances. Palpitation was present in four patients; of these, one noted relief with either hydergine or the inert 
TABLE I

The effect of treatment With Hydergine upon the Blood Pressure AND SYMPTOMS, DURING THE Hospital Period

\begin{tabular}{|c|c|c|c|c|}
\hline \multirow{2}{*}{ Case } & \multirow{2}{*}{ Symptoms } & \multicolumn{3}{|c|}{ Average daily blood pressure readings at rest } \\
\hline & & Before therapy & Inert control & Hydergine \\
\hline $\begin{array}{l}1 \\
2^{*} \\
3^{*} \\
4^{*} \\
5 \\
6 \\
7^{*} \\
8^{*} \\
9^{*} \\
10 \\
11 \\
12^{*} \\
13^{*} \\
14^{*} \\
15^{*} \\
16^{*} \\
17^{*}\end{array}$ & $\begin{array}{l}\text { Relieved } \\
\text { Relieved } \\
\text { Relieved } \\
\text { Not improved } \\
\text { Not improved } \\
\text { Not improved } \\
\text { Relieved } \\
\text { Relieved } \\
\text { Relieved } \\
\text { Improved } \\
\text { Improved } \\
\text { Improved } \\
\text { Relieved } \\
\text { Relieved } \\
\text { No symptoms } \\
\text { Relieved } \\
\text { Relieved }\end{array}$ & $\begin{array}{l}214 / 132 \\
176 / 116 \\
154 / 106 \\
186 / 124 \\
230 / 128 \\
230 / 110 \\
164 / 108 \\
182 / 110 \\
180 / 130 \\
236 / 136 \\
230 / 138 \\
266 / 144 \\
186 / 112 \\
222 / 130 \\
162 / 110 \\
154 / 106 \\
210 / 124\end{array}$ & $\begin{array}{l}216 / 132 \\
176 / 118 \\
146 / 106 \\
170 / 116 \\
210 / 122 \\
226 / 108 \\
160 / 104 \\
180 / 112 \\
170 / 122 \\
228 / 126 \\
236 / 140 \\
246 / 140 \\
182 / 110 \\
214 / 126 \\
168 / 108 \\
160 / 104 \\
214 / 120\end{array}$ & $\begin{array}{l}206 / 126 \\
162 / 100 \\
130 / 90 \\
150 / 100 \\
190 / 114 \\
228 / 100 \\
144 / 86 \\
162 / 94 \\
150 / 102 \\
214 / 120 \\
214 / 132 \\
200 / 110 \\
152 / 88 \\
154 / 90 \\
134 / 86 \\
142 / 88 \\
182 / 102\end{array}$ \\
\hline
\end{tabular}

* Cases showing a drop of more than $14 \mathrm{~mm}$. in diastolic pressure on treatment, as compared with the control period readings.

preparation and 3 with hydergine alone. When complete relief was obtained in 10 cases, it was noted that such relief was not obtained during the period of dosage with the inert control:

In Case 12, who had malignant hypertension at the age of 44, repeated intensely severe headaches associated with vomiting and hypertensive crises had been a feature before admission. This patient believed such headaches could be partially relieved by intramuscular femergin. Two such crises occurred while she was under observation in the ward before treatment was begun, and in both she was severely ill, the diastolic pressure rising to $180 \mathrm{~mm}$. on one occasion and $172 \mathrm{~mm}$. $\mathrm{Hg}$ on the other. During a crisis, intravenous injection of $0.6 \mathrm{mg}$. hydergine had little effect; intravenous injection of $40 \mathrm{mg}$. of pentamethonium iodide resulted in rapid reduction of headache and cessation of vomiting for a period of six hours, together with a fall in blood pressure to $130 \mathrm{~mm}$. diastolic. Following treatment with hydergine, however, this patient had no further crises during her period of fourteen weeks in hospital. No relief was obtained during the two crises observed by the parenteral use of femergin.

(3) Effects on the retince. It is difficult to state what were the real effects on the retinal picture. There is no doubt that in cases with marked spasm of the arterioles (Cases 2, 4, and 12) such vessels were less spastic on treatment than before it. In Case 4, a recent hæmorrhage was noted on admission and a further one occurred within four days. On starting treatment, retinal spasm disappeared, and no further hæmorrhage or exudates occurred during the next month.

On the other hand, several hæmorrhages occurred during therapy in Case 12, where papillœdema was also present, and which gradually regressed during the period of observation of 14 weeks.

(4) Renal function. No significant change in renal function was noted as indicated by the urea range test.

(5) Electrocardiogram. Left ventricular hypertrophy was present in 10 subjects. No significant change in the 12-lead electrocardiogram occurred during treatment.

(6) Heart size. No significant changes were noted radiologically.

(7) Side-effects. The following side-effects observed were:

(i) Nasal congestion. 'This was common, and occurred on treatment in 12 subjects. Of 
these, 7 experienced the sensation during the intravenous test. In only one, however, was it severe enough to cause discomfort (Case 4). This symptom was transient, lasting 3-6 days in nine subjects and in three it persisted for 14 days and was present on discharge from hospital.

(ii) Nausea. This occurred in three subjects and was relieved by reduction of therapy in two, and in none was it caused by the inert preparation. In these two subjects, nausea was maximum one hour after.intramuscular injection. In one patient (Case 4) nausea was severe and accompanied by lassitude, pain behind the eyes and vomiting, following discharge from hospital, even in as small a dose as 10 minims t.i.d. Vomiting did not occur in any case while in the hospital, however.

(iii) Drowsiness. This was noticed in a mild form by five subjects during treatment; three others, while not drowsy, volunteered the information that they slept much better during treatment. There were no such effects during therapy with the inert preparation.

(iv) Slowing of the pulse rate occurred in 13 subjects while on treatment, by $10-20$ beats a minute.

(b) Out-patient treatment.

In all subjects, following discharge from the ward, oral therapy was continued for one month in a dose of 35 minims t.i.d. by mouth. For the following month subjects were given a similar dose of the inert preparation, unknown to them, and then all treatment was stopped for a further month. After this, continued dosage with the active preparation was resumed.

(1) Effects on blood pressure. Of the 17 cases observed, the blood pressure was significantly lower on the hydergine treatment than on the inert preparation or on no treatment in 12 instances. Of the other 5, one was arteriosclerotic (Case 5) and emotionally unstable. Another (Case 10), had marked peripheral and retinal arteriosclerosis. Case 4 could not continue treatment on account of side-effects. Case 6 is of some interest. She was emotionally unstable and proved at follow-up to be quite unreliable. Her many symptoms were relieved equally by hydergine and the inert preparation. She did not trouble to procure a suitable measure for the hydergine and had by way of compromise take three tablespoonfuls a day for a period of two weeks. This was a dose of $42 \mathrm{mg}$. a day. No ill effects of over-dosage resulted in this arteriosclerotic subject. Case 1 also failed to respond satisfactorily.

(2) Effects on symptoms. Case 1 was symptom-free at home on treatment and was able to take up light work in a garage. On ceasing treatment after four weeks, he became depressed, tired, and had severe headaches, which were not relieved by treatment with the inert preparation but which disappeared with the active one. Case 2 felt better and less tired on treatment, but could do a full day's work as a housewife with two young children whether on treatment or not. Case 3 worked on treatment as a night sister in a hospital-work which she believed herself incapable of doing before admission. On the inert preparation, she felt tired and was subject to palpitation (extrasystoles) and felt like giving up her job. When treatment was renewed, so apparently was her vigour. Case 4, who had nausea and nasal congestion in the ward, did not do well. On full doses at home, he developed headache, nausea, vomiting, pain behind the eyes and was "dead-beat" and unfit for anything. On stopping treatment, he became reasonably well again, apart from his morning headache. He had no such side effects on the inert preparation, but on returning to treatment on a smaller dose of 10 minims t.i.d. he again had these symptoms, and therapy was stopped. Cases 5 and 6 were unreliable on account of their emotional instability. Case 7 became symptom-free at home on treatment but not on the control. Case 8 responded similarly. Case 9 returned to full work and had no complaints apart from coldness and stiffness in the right hand, much relieved by physiotherapy. Case 10 was better on both inert and control preparations; he was a very anxious, worrying man who, when given confidence improved greatly, but had many symptoms while off all treatment. Case 11 did not return to full work and two months after discharge developed renal failure. Case 12, who had malignant hypertension, stated that she felt very well for four months after treatment during which she led a lazy life and had no further head- 
ache. Case 13 had no complaints, doing energetic housework on hydergine, but developed headache and tiredness on the inert preparation. Case 14 remained symptom free on treatment, but complained of tiredness and lack of interest in her housework while on the control or no treatment. Case 15 had no symptoms before, during, or after treatment. Case'16 returned to work as a policeman on the beat feeling well during treatment apart from tiredness while on night work. Case 17 continued work in a bus company and, apart from old-standing fibrositis of the neck and shoulders, remained well on treatment; he has only been followed up for three months.

(3) Effects on the retina. In no case was there advance in the degree of spasticity of the retinal vessels, and in no case did exudate or hæmorrhage appear, although these had been previously present in Case 4, in whom an acute progressive arteriolar change had at least been halted. In Case 12 papilloedema had practically disappeared after three months.

(4) Effects on electrocardiogram and heart size. None of significance were noted.

(5) Side-effects. Nasal congestion present at discharge from hospital in three cases, disappeared within one month in two of them. In Case 4 it persisted as long as treatment was given.

\section{SumMaRY AND CONCLUSIONS}

The effect of intravenous injection of $0.3 \mathrm{mg}$. of hydergine in 50 hypertensive patients was to lower the blood pressure to a varying extent in each instance. As a result of this survey the impression was formed that those subjects with minimal peripheral arteriosclerosis and good renal function were most liable to show a satisfactory response. The most marked response was seen in three subjects with malignant hypertension and good renal function.

Reduction of the pressor response to cold is an interesting feature and in keeping with the results of von Kappert (1947) and Freis et al. (1949). Whatever the initial lability of the blood pressure before hydergine was administered, the average response to the cold pressor test following injection was diminished and readings showed a rise of some $15 \mathrm{~mm}$. systolic and $10 \mathrm{~mm}$. diastolic half an hour after injection. From this it is reasonable to suggest that hydergine may be expected to prevent the transient rises of pressure to which hypertensive subjects are liable, and further, to prevent repeated hypertensive encephalopathy in certain subjects; such prevention did in fact occur in the one subject with malignant hypertension who received a therapeutic regime.

No catastrophic fall in pressure did occur during injection even with reduction of injection time to 30 seconds. Further, nasal congestion was the only side-effect noted after injection and presumably due to stellate ganglion block. "Opening up" of spastic retinal arterioles was noted in 11 cases, within ten minutes of intravenous injection.

Combined oral and parenteral therapy resulted in a significant fall in diastolic pressure in 12 subjects, all of whom had good renal function and minimal arteriosclerosis.

Relief of symptoms of headache and tiredness and palpitations occurred during treatment in 13 subjects and in 10 was complete; in none of these 10 was there similar relief while taking the inert preparation. Hydergine probably increases cerebral blood flow by its vasodilator action and the reduction of headache may be related to this action.

Side effects were only unpleasant enough in one subject to result in cessation of therapy; in this subject nausea and vomiting were present even when small doses were being given and the symptoms were considered to be due to excitation of the vomiting centre, similar to that which occurs in ergot poisoning. Drowsiness, present in 5 subjects, was mild and could be associated with central nervous depression. Nasal congestion, as mentioned, was considered to be a sign of stellate ganglion block, and was the commonest side-effect, occurring in 12 out of 17 subjects; it was noted by Bluntschli and Goetz (1947) and repeatedly since then by other authors. The slowing of heart rate as noted by Rothlin (1944) was shown to be partly inhibited by atropine by Wilkins et al. (1949). This slowing may be due to the property possessed by ergot alkaloids of inactivating cholinesterase; it is possible that it is due to central nervous depression.

Follow-up of the 16 benign cases demonstrated that 10 of the 11 subjects, with good renal 
function and a labile pressure and minimal arteriosclerosis, were able to do a full day's work and maintain a lower blood pressure on therapy than that recorded while on no treatment or on the inert preparation; further, none showed advance of retinopathy. The diastolic pressure was maintained below $90 \mathrm{~mm}$. in three subjects at rest, who were leading active normal lives.

It would seem justifiable on the evidence of this preliminary observation to investigate the potentialities of these dihydrogenated derivatives or ergot further by clinical trial. Probably most subjects can take a larger dose than that used in this survey although this may not be desirable. Hydergine does not remove the cause of hypertension. The reduction of pressure obtained in the treated cases did not, over this short period of follow-up, cause harm to any subject. If such reduction can be maintained over a period of years, the increased bodily wear and tear to which hypertensive subjects are liable may be reduced. Further, if the acute progressive phases of hypertension can be prevented in younger subjects, then benefit may be said to have been obtained.

Comparison with the results of surgical sympathectomy as a method of treatment can only be made when a larger number of subjects have been followed up over a period of years.

The results of this clinical trial do not prove that hydergine acts entirely by producing adrenergic blockade in man. It is still possible that at least some of the effects observed were due to central nervous depression and elucidation of this point will be of the utmost interest.

I wish to express my thanks to Dr. A. Rae Gilchrist for permission to publish these cases and for his advice and encouragement in the preparation of this paper; to Messrs. Sandoz for supplies of hydergine and technical advice, and to Mr Shepley, University Artist, Department of Surgery, University of Edinburgh, for his skilful preparation of the diagrams.

\section{REFERENCES}

Bello, C. T., Moss, W. G., and Weiss, E. (1950). Amer. J. Med., 8, 634.

Bluntschli, H. J., and Goetz, R. H. (1947). South African med. J., $21,382$.

Cerletti, A., and Kallenberger, A. (1948). Helv. physiol. Acta., 6, 795.

Dale, H. H. (1906). J. Physiol., 34, 163

Freis, E. D., Stanton, J. R., and Wilkins, R. H. (1948). Amer. J. med. Sci., 216, 163.

Von Kappert, A., Baumgartner, P., Daguet, A., Erard, H., Rupp, F., Schorer, D., and Zurcher, H. P. (1949). Helv. med. Acta. Supplementum, XXII, 16, 1.

Keith, M. A., Woolf, B., and Gilchrist, A. R. (1949). Brit. Heart J., 11, 287.

Nickerson, M. (1949). J. Pharmacol., 95, 268.

Rothlin, E. (1944). Helv. physiol. Acta., $2,648$.

- (1947). Bull. Schweiz. Acad. med. Wisch., $2,249$.

, and Cerletti, A. (1949). Deutsch. Ges. kreislauffschg. Nauheim.

Stoll, A. (1920). Verh. Schweiz. Naturforsch. Ges., 101, 190.

-, and Hofmann, A. (1942). Helvet, chim. Acta., 26, 1570.

(1943). Helvet chim. Acta., 26, 2070.

Wagener, H. P., and Keith, N. M. (1939). Medicine., 18, 317.

Wilkins, R. H., Freis, E. D., and Stanton, J. R. (1949). J. Amer. med. Assoc., 140, 261 